\title{
Fatal Acute Hemolytic Transfusion Reaction due to Anti-Wra
}

\author{
Tanaz Bahria Kim de Bruyn ${ }^{\mathrm{b}}$ Rineke Leys ${ }^{\mathrm{a}} \quad$ Floor Weerkamp $^{\mathrm{b}}$ \\ ${ }^{a}$ Department of Hematology, Maasstad Hospital, Erasmus Medical Center Rotterdam, Rotterdam, the Netherlands; \\ b Laboratory of Clinical Chemistry, Hematology and Transfusion Medicine, Maasstad Hospital, Erasmus Medical Center Rotterdam, \\ Rotterdam, the Netherlands
}

\section{Keywords}

Hemolytic transfusion reaction $\cdot$ Wra blood group antigen - Anti-Wr ${ }^{\mathrm{a}}$. Low-frequency blood group antigen . Direct antiglobulin test . DAT . Indirect antiglobulin test . IAT

\section{Summary}

Background: The $\mathrm{Wr}^{\mathrm{a}}$ blood group antigen is a low-frequency antigen. Antibody screening sets used in pretransfusion laboratory investigations usually do not contain a $\mathrm{Wr}(\mathrm{a}+)$ cell. If subsequent cross-matching is performed without indirect antiglobulin test (IAT), $\mathrm{Wr}^{\mathrm{a}}$ antibodies reacting with donor red blood cells (RBCs) will be missed. For reasonable economic and time-saving arguments the risk of missing the detection of a potential clinically relevant antibody is worldwide accepted. Case Report: A 66 -year-old women with a negative antibody screen rapidly deteriorated after she received two units of RBCs for symptomatic anemia after hip surgery. Diagnosis of a transfusion reaction was obscured by pre-existing and nonspecific symptoms. Laboratory investigation indicated acute hemolysis. Cross-matching in IAT was positive for the first unit, and an extended antibody identification panel showed reactivity with $\mathrm{Wr}(\mathrm{a}+)$ cells. The patient did not respond to supportive therapy and died within $48 \mathrm{~h}$ after the start of transfusion. Conclusion: This dramatic case provides further evidence on the clinical relevance of Wra blood group antibodies. In addition, it underlines the clinical importance of risk awareness in the blood transfusion chain and the possible complexity in relation to patient monitoring in daily transfusion practice.

\section{(c) 2018 The Author(s)}

Published by S. Karger GmbH, Freiburg

Tanaz Bahri and Kim de Bruyn contributed equally.

\section{Introduction}

The $\mathrm{Wr}^{\mathrm{a}}$ blood group antigen is a low-frequency antigen, which is part of the Diego system. The overall prevalence of $\mathrm{Wr}^{\mathrm{a}}$ antigen in blood donors is approximately $0.1 \%[1,2]$. However, its corresponding antibody is much more prevalent. The prevalence of anti- $\mathrm{Wr}^{\mathrm{a}}$ is ranging from 1:56 in healthy blood donors [3] to $5.8 \%$ in a range of individuals (blood donors, pregnant women, and hospitalized patients) [4]. Anti- $\mathrm{Wr}^{\mathrm{a}}$ is capable of causing severe hemolytic transfusion reactions (HTRs) [5] as well as hemolytic disease of the newborn [6], but because of the low frequency of $\mathrm{Wr}^{\mathrm{a}}$ antigen severe reactions are relatively uncommon. Only 6 cases of hemolytic transfusion reactions have been described [5, 7-11]. In the Serious Hazards of Transfusion (SHOT) Steering Group reports from 2012 to 2016, 11 cases of anti- $\mathrm{Wr}^{\mathrm{a}}$ causing HTR have been reported, one of which resulted in death of the patient [12] whilst the other cases had minor morbidity [13].

We report a patient with a very severe acute HTR most likely due to anti-Wra $\mathrm{r}^{\mathrm{a}}$. The patient did not respond to supportive therapy and died within $48 \mathrm{~h}$. Because of the severity of the reaction, it raises our concerns to what antigen specificity should be considered for inclusion in the antibody screenings cells.

\section{Case Report}

A 66-year-old Caucasian woman with acute pain in her right hip and decreased hemoglobin $(\mathrm{Hb})$, was admitted to our hospital. Her medical history included diabetes mellitus, osteoarthritis, rheumatoid arthritis and a Girdlestone procedure of the right hip. In the previous 3 years, she received a total of 13 units of RBCs during several episodes of hip surgery.

Under the diagnosis of intra-articular bleeding, she underwent an echo of the hip, which showed no signs of bleeding. Her hemoglobin level at admittance was $8.5 \mathrm{~g} / \mathrm{dl}$ and decreased to $8.0 \mathrm{~g} / \mathrm{dl} 1$ day after. Antibody screen using gel column agglutination (ID-DiaCell I-II-III in a low-ionic-strength saline indirect antiglobulin test (LISS-IAT) in a LISS/Coombs gel card containing anti-IgG and C3d from BioRad (Hercules, CA, USA) was negative, and the patient was 


\begin{tabular}{llll}
\hline & At presentation & $10 \mathrm{~h}$ after first unit & 13 h after first unit \\
\hline Hb, g/dl & 8.5 & 8.9 & 7.6 \\
Bilirubin $(<18 \mu \mathrm{mol} / \mathrm{l})$ & 12 & 166 & 132 \\
ALT $(0-31 \mathrm{U} / \mathrm{l})$ & 25 & 463 & 557 \\
AST $(0-31 \mathrm{U} / \mathrm{l})$ & 28 & 839 & 1,150 \\
LD $(0-250 \mathrm{U} / \mathrm{l})$ & 247 & 1,995 & 2,312 \\
Creatinine $(<90 \mu \mathrm{mol} / \mathrm{l})$ & 70 & 212 & 263 \\
Haptoglobin $(0.3-2.0 \mathrm{~g} / \mathrm{l})$ & 1.1 & $<0.1$ & - \\
pH $(7.35-7.45)$ & - & 7.17 & 6.99 \\
HCO3- $(21-28 \mathrm{mmol} / \mathrm{l})$ & - & 9 & 5 \\
pCO2 $(35-48 \mathrm{~mm} \mathrm{Hg})$ & - & 24 & 22 \\
pO2 $(75-100 \mathrm{~mm} \mathrm{Hg})$ & - & 84 & 290 \\
\hline
\end{tabular}

unknown in the Transfusion Register for Irregular Antibodies and X match problems (TRIX) in the Netherlands. Two units of ABO-identical RBCs were cross-matched by immediate-spin technique at room temperature. Both were considered compatible and issued for transfusion.

One hour after the transfusion start of the first unit, the patient complained of having chills and pain in the back and her neck. Her temperature also increased to $38.3^{\circ} \mathrm{C}$. By then, the first unit of RBCs was completely administered. She began to vomit and complained of abdominal pain. Her blood pressure was $120 / 60 \mathrm{~mm} \mathrm{Hg}$ and her temperature $38.6{ }^{\circ} \mathrm{C}$. This was considered as a mild transfusion reaction, because the majority of her complaints were pre-existent and non-specific. She was monitored frequently, and the second unit was administered. The temperature decreased after thee second unit to $37.0^{\circ} \mathrm{C}$, her blood pressure was $85 / 55 \mathrm{~mm} \mathrm{Hg}$, her heart rate $76 \mathrm{bpm}$, and her oxygen saturation $94 \%$. The patient complained of dyspnea and abdominal pain. She was treated with oxygen and normal saline infusion, after what she remained stable over the night. In the morning the patient became more dyspneic and tachypneic, with a blood gas showing $\mathrm{pH} 7.17, \mathrm{CO}_{2} 24 \mathrm{~mm} \mathrm{Hg}$, bicarbonate $9 \mathrm{mmol} / \mathrm{l}$, base deficit $-18 \mathrm{mmol} / \mathrm{l}$, and $\mathrm{O}_{2} 84 \mathrm{~mm} \mathrm{Hg}$. Further laboratory tests showed acute renal insufficiency and also severe hepatic abnormalities with increases in serum transaminases and unconjugated bilirubin.

The patient was treated with hydrocortisone and directly transferred to the intensive care unit, where she received supportive care. Nevertheless, she deteriorated rapidly and developed an adult respiratory distress syndrome in combination with multi-organ failure. She died within $48 \mathrm{~h}$ after the start of the first transfusion

Biochemical investigation at the time of detoriation showed a positive direct antiglobulin test (DAT), low haptoglobin of less than $0.1 \mathrm{~g} / \mathrm{l}$, high total bilirubin of $166 \mu \mathrm{mol} / \mathrm{l}$, and high lactate dehydrogenase of 1,995 U/l. Laboratory tests also showed severe hepatic abnormalities with an increase in serum transaminases, alkaline phosphatase, and gamma-glutamyl transpeptidase as well as the appearance of spherocytes on the blood film (table 1).

Laboratory testing for a possible transfusion reaction was performed. The $\mathrm{ABO}$ blood groups of the patient and the donor RBCs were confirmed. Both $\mathrm{RBC}$ units were cross-matched using a LISS-IAT in a BioRad LISS/Coombs gel card. The first unit showed agglutination (3+) with the patient's pretransfusion blood.

In material before transfusion, the antibody screen (BioRad ID-DiaCell I-IIIII) and DAT (polyspecific antihuman globulin in a BioRad LISS/Coombs card) were negative. After transfusion, the antibody screen was still negative, but the DAT was weakly positive. Testing in a BioRad DC-Screening II card with monospecific IgG and C3d showed only anti-IgG antibody activity. An antibody identification panel (ID-DiaPanel in a LISS/Coombs card, BioRad) showed a positive reaction (3+) with one test cell, which was positive for the $\mathrm{Wr}^{\mathrm{a}}$ antigen. The regional reference laboratory confirmed the presence of anti- $\mathrm{Wr}^{\mathrm{a}}$ in pretransfusion blood using two additional test cells. All other panel cells, including low-frequency antigens $\mathrm{C}^{\mathrm{w}}, \mathrm{Lu}^{\mathrm{a}}, \mathrm{Kp}^{\mathrm{a}}$, and $\mathrm{Co}^{\mathrm{b}}$ as well as the autocontrol were negative. Antigen typing showed the first donor RBC unit to be positive for $\mathrm{Wr}^{\mathrm{a}}$. The patient was shown to be negative for the $\mathrm{Wr}^{\mathrm{a}}$ antigen. The reference laboratory also confirmed the DAT after transfusion to be weakly positive for IgG and negative for IgA, IgM, C3c, and C3d. An eluate (acid elution using ELU-Kit II from Immucor (Dreieich, Germany) prepared from the patient's RBCs did not react with any of the tested panel cells, including $\operatorname{Wr}(\mathrm{a}+)$ test cells, in the PEG-IAT technique. IAT (LISS) in the presence of diclofenac was negative.

Autopsy showed no signs of infection, blood cultures of transfused blood remained negative. The ischemic findings in the bowel and kidneys were consistent with multi-organ failure and shock.

\section{Discussion}

Acute HTR is a serious adverse event with a mortality risk of about one in 30 reactions [14]. It is a result of rapid destruction of donor erythrocytes by preformed recipient antibodies. The majority of acute HTRs is due to ABO incompatibility, mostly as a result of procedural error. Some acquired allo-antibodies can less frequently cause an acute HTR, such as antibodies against antigens from the Rh, Kell, Kidd, and Duffy blood group system. Only a few cases have been described [5, 7-11] in which an acute HTR was due to anti-Wra ${ }^{\mathrm{a}}$, with one fatal case which was also caused by other factors than the HTR [8]. According to the Serious Hazards of Transfusion Steering Group, HTRs due to anti- $\mathrm{Wr}^{\mathrm{a}}$ are mild and are mostly unnoticed [13]. However, the SHOT report 2015 describes one elderly male patient with multiple comorbidities who died due to HTR caused by anti-Wra following electronic issue [12].

The data in several studies show that there is a small risk of missing antibodies if the antiglobulin test phase of the crossmatch is not performed in situations of a negative screening for allo-antibodies [15]. Considering the overall prevalence of anti-Wra ${ }^{\mathrm{a}}(3 \%)$ and the frequency of $\mathrm{Wr}^{\mathrm{a}}$ antigen in blood donors $(0.1 \%)[1,2]$, the chance for a patient to receive a $\mathrm{Wr}^{\mathrm{a}}$-mismatched transfusion is 1 : 16,000 per cell unit [16]. The described HTRs associated with anti$\mathrm{Wr}^{\mathrm{a}}$ are likely mild, and because of its relative rareness it was concluded that the addition of $\mathrm{Wr}^{\mathrm{a}}$ to the list of antigens present on the antibody screening cells would increase the costs and was not necessary [5].

In retrospect, our patient developed symptoms and clinical signs of a very severe acute HTR. Early clinical detection by patient monitoring during the blood transfusion was complicated by the 
pre-existent complaints mimicking acute HTR clinical signs. The diagnoses of HTR was supported by the biochemical investigations, including elevated bilirubin, low haptoglobin, and the appearance of spherocytes, renal insufficiency, and ultimately shock and multi-organ failure. An infection was excluded by negative blood cultures, and the autopsy revealed no other cause than ischemic findings consistent with shock. Diclofenac-induced hemolysis [17] was ruled out by the absence of antibodies against diclofenac and the fact that there was no hemolysis before transfusion. In post-mortem investigations, there was no evidence for other causes as listed in the differential diagnosis.

The HTR was most likely caused by anti-Wra ${ }^{\mathrm{a}}$, as no other antibodies were found in the patient's plasma and the IAT crossmatch was positive with the $\mathrm{Wr}(\mathrm{a}+)$ donor. However, the DAT was only weakly positive, and no anti- $\mathrm{Wr}^{\mathrm{a}}$ could be detected in the acid eluate, although an eluate is usually more sensitive by concentration of the antibody. Presumably the eluate was negative due to the fact that it was tested in the PEG-IAT technique, whereas the plasma of the patient reacted positive with the $\mathrm{Wr}(\mathrm{a}+)$ donor cells in the LISS-IAT technique. Other elution techniques or a repeat eluate were unfortunately not considered at the time. The presence of an antibody against another low-frequency antigen cannot be excluded. The chance that the donor was positive for this hypothetical other low-frequency antigen is, however, extremely small.

Arriaga et al. [2] concluded that the presence of anti- $\mathrm{Wr}^{\mathrm{a}}$ may be facilitated by a hyperactive immune system. Our patient was known to suffer from rheumatoid arthritis, which possibly facilitated the development of anti-Wra $\mathrm{r}^{\mathrm{a}}$. The antibody could also be formed after a previous RBC transfusion. Unfortunately, of the 13 units the patient received in the years before, only 4 were typed for $\mathrm{Wr}^{\mathrm{a}}$ antigen (these were negative).

This case highlights the non-detection of antibodies to low-frequency blood group antigens as a potential limitation of the immediate-spin or computer crossmatch [18-20]. The incompatibility of patient and donor would have been detected if a full IAT crossmatch had been used. As pointed out by Garratty [15], the 'type and screen' approach is approved by international guidelines, and the very small risk it poses has been accepted. It is however essential for all personnel involved in the transfusion chain to be aware of this risk and take immediate action if signs and symptoms of a possible transfusion reaction occur. As the AABB Technical Man- ual points out, early recognition, prompt cessation of the transfusion, and further evaluation are key to a successful outcome. Initially, a mild transfusion reaction was considered, but ignored as a trivial observation. Due to the pre-existent clinical symptoms of the patient, the gradual deterioration of the patient was masked. As a consequence, subsequent laboratory investigation to exclude or prove an HTR was not undertaken. The addition of $\mathrm{Wr}^{\mathrm{a}}$ to the list of antigens present on the RBCs used for antibody detection would increase the cost and time to unit release $[5,21]$. But presumably, detecting the incompatibility could in this specific case have prevented the fatal course. In general, the detection and hemolytic potential of antibodies to low-frequency blood group antigens are not only a matter of concern in relation to blood transfusion but also in hemolytic disease of the newborn [6].

\section{Conclusion}

Here we describe the development of a fatal HTR most likely caused by an anti-Wra allo-antibody. This case demonstrates the potential clinical significance of anti-Wra and underlines the need for gaining additional understanding and knowledge on the involvement of anti-Wra in HTRs. The post-transfusion laboratory analysis demonstrates the need for an elaborate laboratory protocol for antibody characterization in case of an HTR. This case may shed new light on the earlier conclusions that screening panels should never contain $\mathrm{Wr}(\mathrm{a}+)$ cells and that generally it is safe enough to assign a blood transfusion by 'type and screen' procedure without performing crossmatch tests. Meanwhile, continuous awareness on the minor but serious risk of an HTR due to antibodies to low-frequency antigens with regard to patient monitoring during blood transfusion is required. Considering the interpretation of doubtful clinical signs and symptoms that may evolve due to a transfusion reaction, we recommend early laboratory investigation in complex situations.

\section{Disclosure Statement}

The authors declare that they have no conflict of interest relevant to the present manuscript.

\section{References}

1 Wallis JP, Hedley GP, Charlton D, Parker PC, Scott Y, Chapman CE: The incidence of anti-Wra and Wra antigen in blood donors and hospital patients. Transfus Med 1996;6:361-364.

2 Arriaga F, Llopis F, de la Rubia J, Carpio N, Moscardó J, Marty ML: Incidence of Wra antigen and anti-Wra in a Spanish population. Transfusion 2005;45:13241326.

3 Greendyke RM, Banzhaf JC: Ocurrence of anti-Wr a in blood donors and in selected patient groups, with a note on the incidence of the Wr a antigen. Transfusion 1977;17:621-624.
4 Schonewille $\mathrm{H}$, van Zijl AM, Wijermans PW: The importance of antibodies against low-incidence RBC antigens in complete and abbreviated cross-matching. Transfusion 2003;43:939-944.

5 Cherian G, Search S, Thomas E, Poole J, Davies SV, Massey E: An acute haemolytic transfusion reaction caused by anti-Wr. Transfus Med 2007;17:312-314.

6 Squires A, Nasef N, Lin Y, Callum J, Khadawardi EM, Drolet C, Core D, Simmons B: Hemolytic disease of the newborn caused by anti-Wright (anti-Wra): case report and review of literature. Neonatal Netw 2012; 31:69-80.
7 Van Loghem JJ, Hart M, Bok J: Two further examples of the antibody anti-Wra. Vox Sang 1955;5:130-134.

8 Metaxas MN, Metaxas-Buehler M: Studies on the Wright blood group system. Vox Sang 1963;8:707716

9 Bunting-Lewis K, Ebbs A: Transfusion reaction caused by anti-Wra in a unit issued by electronic crossmatch. Transfus Med 2005;15(suppl 1):54.

10 Boctor FN: Overt immediate hemolytic transfusion reaction attributable to anti- $\mathrm{Wr}(\mathrm{a})$. Immunohematology 2008;24:113-115. 
11 Shulman IA: The risk of an overt hemolytic transfusion reaction following the use of an immediate spin crossmatch. Arch Pathol Lab Med 1990;114:412-414.

12 Bolton-Maggs PHB: Conference report: the 2015 SHOT symposium and report - what's new? Transfus Med 2015;25:295-298.

13 Bolton-Maggs PHB: SHOT conference report 2016: serious hazards of transfusion - human factors continue to cause most transfusion-related incidents. Transfus Med 2016;26:401-405.

14 Bakdash S, Yazer MH: What every physician should know about transfusion reactions. CMAJ 2007;177: 141-147.
15 Garratty G: How concerned should we be about missing antibodies to low incidence antigens? Transfusion 2003;43:844-847.

16 Hoffmann JJ: Anti-Wr(a): to screen or not to screen? Transfusion 2007;47:948-949; discussion 949.

17 Ahrens N, Genth R, Kiesewetter H, Salama A: Misdiagnosis in patients with diclofenac-induced hemolysis: new cases and a concise review. Am J Hematol 2006; 81:128-131.

18 Molthan L: Intravascular hemolytic transfusion reaction due to anti-Vw+Mia with fatal outcome. Vox Sang 1981;40:105-108.
19 Mun SH, Lee SH, No MY: A case of acute hemolytic transfusion reaction due to anti-Di(a) antibody - a case report. Korean J Anesthesiol 2012;63:353-356.

20 Joyce AJ, Quantock KM, Banh R, Liew YW: Hemolytic transfusion reaction attributable to anti-Dia. Immunohematology 2017;33:6-8.

21 Coluzzi S, De Nicolò MC, Quattrocchi L, Neri A, Ferruzzi I, Girelli G: Should pre-transfusion screening RBC panels contain $\mathrm{Wr}(\mathrm{a}+)$ cells? Transfus Med 2010; 20:337-340. 